\title{
Glasses in bone regeneration: a multiscale issue
}

\author{
Antonio J. Salinas \& Maria Vallet-Regí* \\ Departamento de Química Inorgánica y Bioinorgánica. Facultad de Farmacia. Universidad \\ Complutense de Madrid. Plaza Ramón y Cajal s/n. 28040 Madrid. Spain. \\ Networking Research Center on Bioengineering, Biomaterials and Nanomedicine (CIBER- \\ BBN), Madrid, Spain. \\ I+12 Instituto Investigación 12 de Octubre, Madrid, Spain
}

\author{
* Corresponding author \\ Maria Vallet-Regi \\ Departamento de Quimica Inorgánica y Bioinorgánica, Facultad de Farmacia, \\ Universidad Complutense de Madrid, \\ 28040 Madrid, Spain. \\ Tel.: +34 91394 1861; fax: +34 91394 1786; \\ E-mail address: vallet@ucm.es
}

\section{Highligths}

- MBGs containing small amounts of $\mathrm{Ga}, \mathrm{Ce}$ or $\mathrm{Zn}$ exhibit high in vitro bioactivity

- The bioactive response is preserved after obtaining 3D scaffolds

- These scaffolds are optimum candidates for bone tissue engineering applications

- $\mathrm{MBG}$ scaffold with $4 \% \mathrm{ZnO}$ exhibit bactericide action against $\mathrm{S}$. Aureus

- The effects of the extra ions is sometimes complex and needs to be investigated 


\begin{abstract}
3D scaffolds based in mesoporous bioactive glasses (MBGs) are being widely investigated to use in bone tissue engineering (TE) applications. These scaffolds are often obtained by rapid prototyping (RP) and exhibit an array of interconnected pores in a hierarchy of sizes. The ordered mesopores network (around $4 \mathrm{~nm}$ in diameter), is optimal for the adsorption and release of bone inductor biomolecules, and the arrangement of macropores over $100 \mu \mathrm{m}$ facilitates the bone cell ingrowths and angiogenesis. Nevertheless MBGs composition can be varied almost infinitely at the atomic scale by including in the glass network oxides of inorganic elements with a therapeutic action. In this article the synthesis and characterization of MBG scaffolds based on the $80 \% \mathrm{SiO}_{2}-15 \% \mathrm{CaO}-5 \% \mathrm{P}_{2} \mathrm{O}_{5}$ (in mol-\%) glass with substitutions up to $3.5 \%$ of $\mathrm{Ga}_{2} \mathrm{O}_{3}$ or $\mathrm{Ce}_{2} \mathrm{O}_{3}$ or $7.0 \%$ of $\mathrm{ZnO}$ is revisited. The substituent inclusion and the RP processing slightly decrease the surface area, the pore volume and the mesoporous order as well as their bioactive response in solutions mimicking blood plasma. However, these values still remain useful for bone TE applications. Results exhibiting the bactericide action of MBG scaffolds containing $\mathrm{ZnO}$ are also presented.
\end{abstract}

\title{
Keywords
}

Mesoporous bioactive glass scaffolds; $\mathrm{Ga}, \mathrm{Ce}$ and $\mathrm{Zn}$ as therapeutical ions; bactericide capability; bone tissue engineering 


\section{Introduction}

Recently bioactive glasses have been widely investigated for diverse clinical applications including the tissue engineering (TE) of bone. Several families can be distinguished in the historical evolution of the bioactive glass investigation, beginning with the first Melt Prepared Glasses (MPGs), discovered by Hench et al in 1969 [1], followed by the bioactive Sol-Gel Glasses (SGGs) also proposed also by Hench in 1991 [2] and the most recent, glasses with ordered mesoporosity designed by Zhao and Vallet-Regi, who investigated independently and reported them for the first time in 2004 and 2006 [3,4]. These glasses denoted as Mesoporous Bioactive Glasses (MBGs) are the main subject of this article.

Simultaneous to the development of glasses with characteristics more and more adapted for use as implant materials, there was a change in the paradigm of the role of bioactive materials used in Orthopedics and Dentistry. In the past, there was a search for materials for the simple substitution and repair of osseous tissues. In 2002 Hench and Polack proposed the search of materials aimed to drive and favor the regeneration of bone, denoted as third generation biomaterials [5]. In their studies they demonstrated that the silicon and calcium ions released from bioactive melt glasses as granules stimulated the genes to persuade the cells to form bone.

The so-called third generation biomaterials can be directly classified in the field of the TE of bone. The first generation are as bioinert as possible and the bioactive or resorbable biomaterials are considered the second generation. It is well known that TE is based on three fundamental pillars: cells, signal molecules and scaffolds [6]. This last pillar, where the MBGs are processed into 3D scaffolds, is considered as an optimal option. An important requirement is that these scaffolds exhibit an interconnected and hierarchical porosity, that is to say, with several orders of magnitude including giant pores (channels) and macropores that allow internal angiogenesis and the interaction with cells. Nevertheless, pores of nanometric size are also required like those exhibited by the mesoporous materials. Such pores allow the inclusion of signal molecules that induce the formation of bone like the Bone Morphogenetic Proteins (BMPs), growth factors like Vascular Endothelial Growth Factor (VEGF), or different fractions of Parathyroid Hormone related Peptide (PTHrP) [7].

With all these ideas in mind, in the last few years $\mathrm{CaO}-\mathrm{P}_{2} \mathrm{O}_{5}-\mathrm{SiO}_{2}$ based $\mathrm{MBG}$ scaffolds (MBG_Sc) are been widely investigated as optimum candidates for bone TE applications. Effectively all these features have special characteristics for the role they 
must play when implanted for the regeneration of osseous tissues. First, the ordered mesoporosity allows the adsorption and release in a controlled manner of the bone induction agents previously mentioned. In addition, these mesoporous channels confer extremely high values of surface area and pore volume to MBGs which increase the already high levels of bioactivity of $\mathrm{CaO}-\mathrm{P}_{2} \mathrm{O}_{5}-\mathrm{SiO}_{2}$ glasses obtained by the quenching of a melt or by sol-gel processing [8,9]. Keeping in mind the essential properties of a 3D scaffold for bone TE applications, several strategies have been proposed for the design of a macroporosity required for cell functions such as the bone cells ingrowths, the nutrients supply and vascularization, as well as for the adhesion and development of the bone cells. These strategies include foaming, freeze drying, fiber bonding or rapid prototyping (RP) technologies [10]. Obviously, in all cases it is very important to confirm that the MBGs powder processing to obtain the scaffolds does not destroy the ordered mesoporosity and bioactivity.

On the other hand, because MBGs are glasses they do not exhibit an exact composition and can be substituted with small amounts of extra oxides of cations featuring important biological actions, such as osteogenesis, antibacterial capacity, angiogenesis or cementogenesis [11-13]. For this reason, there is a general trend to upgrade properties with some of the well known therapeutical ions because of their biological action [14-16]. Figure 1 depicts an approximate time required for in vitro bioactivity for the three families of bioactive glasses and the year of discovering of each family. The biological action of inorganic ions used for upgrade the glasses are also included. 


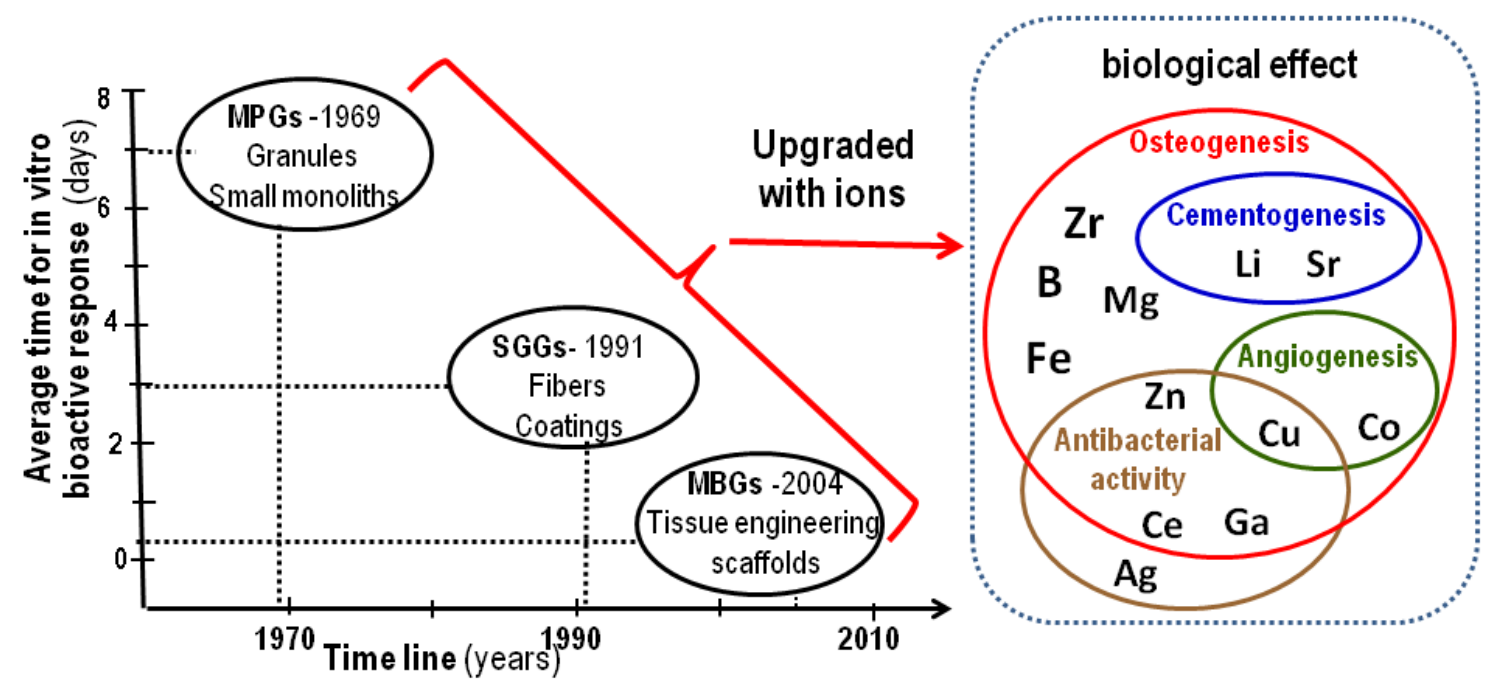

Figure 1. Left: timeline in the discovering of the three families of bioactive glasses and the approximate time required for a standard member of each family was coated by an apatite-like layer after being soaked in a simulated body fluid. Right: some ions investigated to upgrade the glasses and their biological effects.

The three families of bioactive glasses showed on the Figure $\mathbf{1}$ are silicate-based glasses, with the presence of $\mathrm{CaO}$ as essential requirement for bioactivity. The third component use to be $\mathrm{P}_{2} \mathrm{O}_{5}$ which binds calcium producing calcium phosphate nuclei that completely modifies the reactivity of glasses when contact with biological fluids [17]. The development of the three families of glasses was together with an increase of the textural properties (surface area and pore volume) in going from the dense MPGs to the MBGs exhibiting over $500 \mathrm{~m}^{2} / \mathrm{g}$ of surface area and more than $0.5 \mathrm{~cm}^{3} / \mathrm{g}$ of pore volume. The surface area and porosity of MBGs are practically half of the values for pure silica mesoporous materials such as MCM-41 or SBA-15, but they are more than twofold the values of sol-gel glasses with analogous composition [18]. Noticeably such increase of textural properties produces an increase in the kinetics of the bioactive response. However, such increase is not significant in terms of the bone of formation induced by these glasses. More important is the new capabilities in terms of the ability to include and release of biologically active substances in the MBGs pores.

Regarding the biological effect of the extra inorganic ions included in the glasses, osteogenesis was the first feature investigated for bone TE applications. For this reason some of the most important property searched for the extra elements added to upgrade the $\mathrm{SiO}_{2}-\mathrm{CaO}-\mathrm{P}_{2} \mathrm{O}_{5}$ glasses was an osteogenic character. In addition, one of the main problems when a material is implanted in bone is osteomyelitis caused for bacterial infection. Thus, a second important property investigated was the ability of fight against 
infection. For this reason elements with antibacterial ability have been also investigated. Because a biomedical application of bioactive glasses is Dentistry, inorganic ions with cementogenic properties were also investigated. Finally to fulfill some of the mentioned properties is necessary the formation of blood vessels that feed to the cells. Consequently the addition of angiogenic elements is reaching also a great interest.

The main objective of this paper to review the state of the art and perspectives of future of MBG scaffolds based on the $15 \% \mathrm{CaO}-5 \% \mathrm{P}_{2} \mathrm{O}_{5}-80 \% \mathrm{SiO}_{2}$ glass enriched with extra ions to add extra features when implanted that made the more beneficial for the role the will must fulfill when be implanted for the regeneration of the bone tissue. In particular our group has been very interested in the last few years in the substitution of MBGs by (i) up to $3.5 \% \mathrm{Ce}_{2} \mathrm{O}_{3}$, because it was reported that $\mathrm{Ce}^{3+}$ ions reduce the enamel demineralization, and are neuroprotective [19], (ii) up to $3.5 \% \mathrm{Ga}_{2} \mathrm{O}_{3}$, because it was published that $\mathrm{Ga}^{3+}$ ions increase the calcium content in bone, and are antimicrobial [20], and (iii) $\mathrm{ZnO}$ because, in addition to other biological functions, it was reported that $\mathrm{Zn}^{2+}$ ions stimulates the bone formation and exhibit also a bactericide action [21,22]. In the Figure 2 are depicted the role of every one of the elements of the MBG_Sc essential to play their role in bone TE. The biological actions of $\mathrm{Ce}^{3+}, \mathrm{Ga}^{3+}$ and $\mathrm{Zn}^{2+}$ ions, that are the main objective of this paper, is highlighted in the Figure.

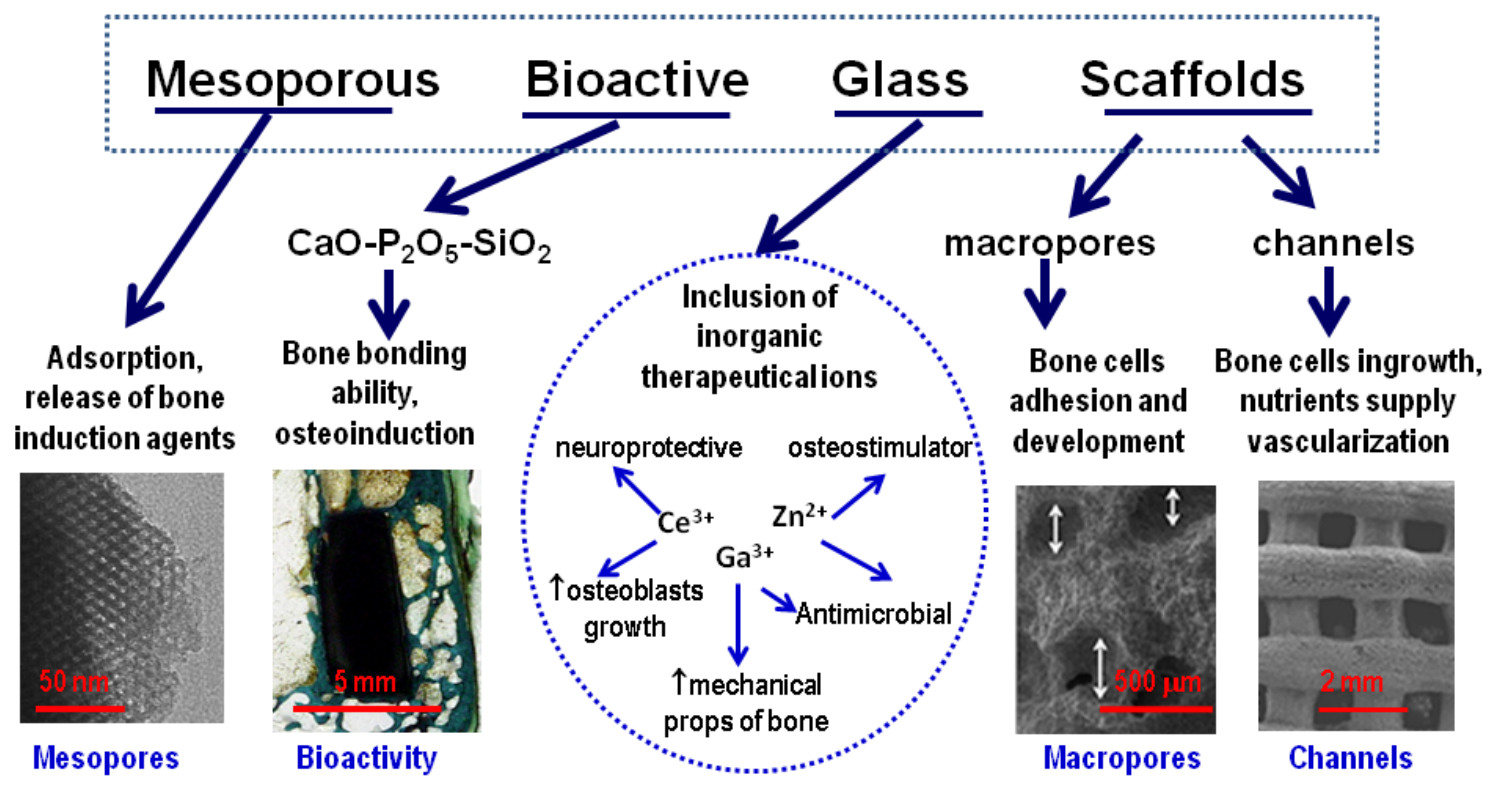


Figure 2. Features that convert MBG scaffolds in optimum candidates for bone TE are summarized. The extra properties that could come for the addition of the inorganic ions revisited in this paper are highlighted.

\section{Mesoporosity, textural properties and bioactivity of substituted MBG powders}

$\mathrm{SiO}_{2}-\mathrm{CaO}-\mathrm{P}_{2} \mathrm{O}_{5}-\mathrm{X}\left(\mathrm{X}=\mathrm{Ce}_{2} \mathrm{O}_{3}, \mathrm{Ga}_{2} \mathrm{O}_{3}\right.$ or $\left.\mathrm{ZnO}\right)$ MBG powders are synthesized by the evaporation induced self-assembly (EISA) method [23]. As reactants are generally used tetraethyl orthosilicate, triethyl phosphate, calcium nitrate tetrahydrate and cerium, gallium or zinc nitrates that are dissolved in ethanol and adding nitric acid as catalyst and Pluronic ${ }^{\circledR} \mathrm{P} 123$ as surfactant [24]. The sol obtained is poured in a Petri dish for the solvent evaporation. Resultant materials are thermally treated for the surfactant and nitrates removal to obtain MBG powders. Other approach for the synthesis of MBGs can be found in ref [25].

Figure 3 shows some results obtained after characterization of MBG powders with compositions obtained by substituting the $15 \% \mathrm{CaO}-5 \% \mathrm{P}_{2} \mathrm{O}_{5}-80 \% \mathrm{SiO}_{2}$ (in mol-\%) glass with amounts of $\mathrm{Ce}_{2} \mathrm{O}_{3}, \mathrm{Ga}_{2} \mathrm{O}_{3}$ up to $3.5 \%$ and $\mathrm{ZnO}$ up to $7.0 \%$. In Fig. 3a it can be observed maxima in the Low Angle X ray Diffraction (LA-XRD) patterns, indicative of mesoporous ordered arrangements. MBGs lack long distance structural order because they are glasses and do not exhibit diffraction maxima in the Wide Angle XRD patterns (WA-XRD). If we observe the LA-XRD pattern correspondent to unsubstituted glass (thereafter will be denoted as blank, B), a sharp maximum at $1.4^{\circ}$ in $2 \theta$, that can be indexed to the (10) reflection of a 2D hexagonal-phase is observed. This maximum is less defined when the $\mathrm{Ce}_{2} \mathrm{O}_{3}$ content in the $\mathrm{MBG}$ increased but is still present in the sample containing $3.5 \% \mathrm{Ce}_{2} \mathrm{O}_{3}$ which is indicative that the ordered arrangements of mesoporous is maintained in all cases. Analogous results were obtained for the $\mathrm{Ga}_{2} \mathrm{O}_{3}$ and $\mathrm{ZnO}$ containing MBGs mot included here by the shake of brevity.

As an example, in the Figure $3 \mathrm{~b}$ the $\mathrm{N}_{2}$ adsorption isotherms of two Cerium-doped MBGs $(0.2 \%$ and $3.5 \%)$ and their corresponding pore size distributions are showed. The curves are identified as type IV isotherms characteristic or mesoporous materials with Type H1 hysteresis loops characteristic of cylindrical pores open at both ends. Figure 3c summarizes relevant properties from $\mathrm{N}_{2}$ adsorption obtained for the three series of samples investigated. As it can be observed the surface area and the pore volume for these MBG powders decrease from a BET surface area of $515 \mathrm{~m}^{2} / \mathrm{g}$ and pore volume of 0.58 $\mathrm{cm}^{3} / \mathrm{g}$ for the unsubstituted MBG, until values in all cases superior to $300 \mathrm{~m}^{2} / \mathrm{g}$ and 0.27 
$\mathrm{cm}^{3} / \mathrm{g}$, i.e. still higher to those of glasses obtained by conventional sol-gel method. Moreover, Figures $3 \mathrm{~d}$ and $3 \mathrm{e}$ correspond respectively to the Scanning Electron Microscopy (SEM) images and the Energy Dispersive X-ray Spectroscopy (EDS) spectrum of the $0.2 \% \mathrm{Ce}_{2} \mathrm{O}_{3}$ containing MBG. The EDS spectrum confirms the presence of cerium in the glass and values of the other glass components very close to the nominal ones.

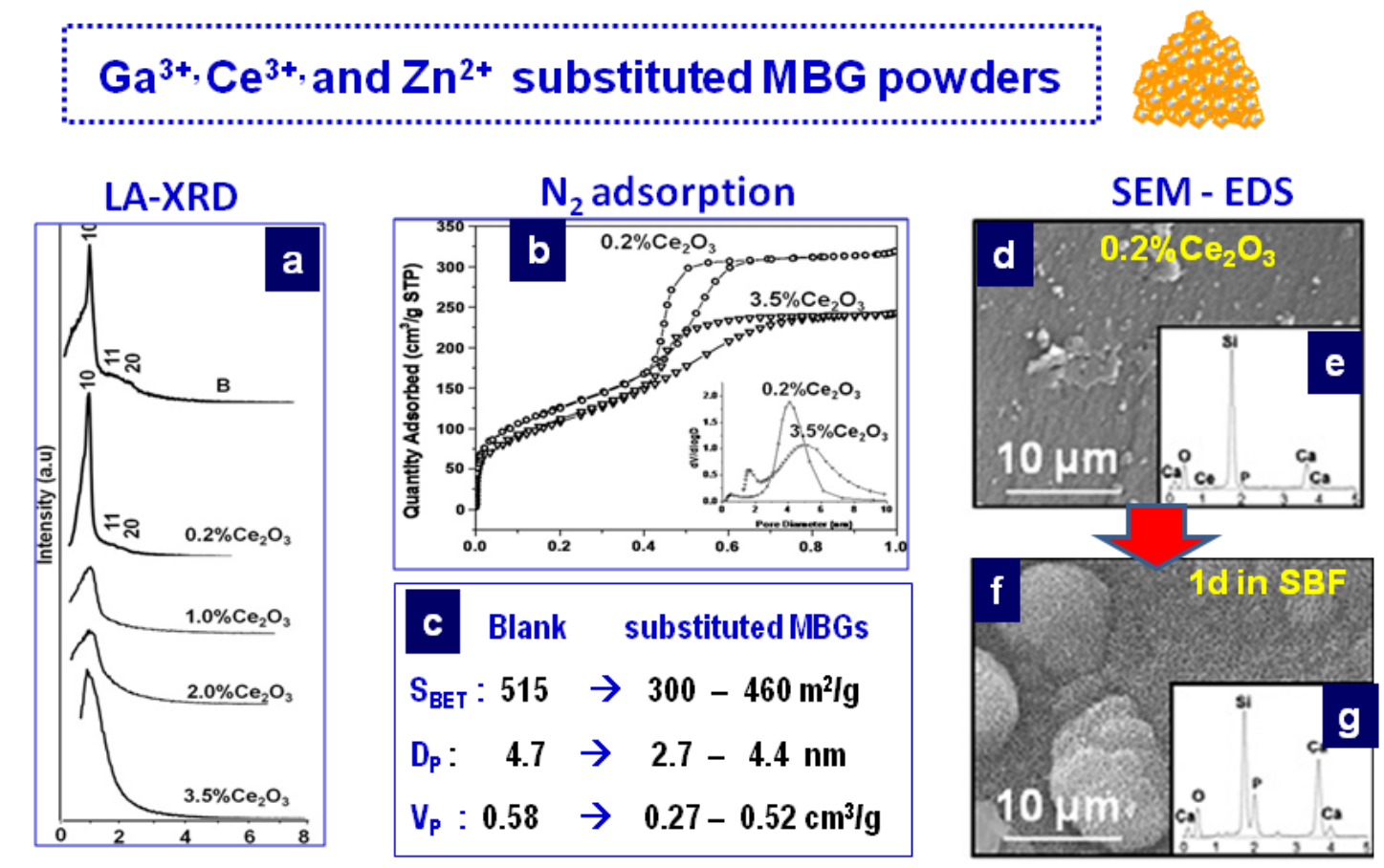

Figure 3. Physical-chemical characterization of $\mathrm{MBG}$ powders based on the $15 \% \mathrm{CaO}-5 \% \mathrm{P}_{2} \mathrm{O}_{5}-80 \% \mathrm{SiO}_{2}$ composition substituted by amounts up to 3.5 mol- $\%$ of $\mathrm{Ce}_{2} \mathrm{O}_{3}$ or $\mathrm{Ga}_{2} \mathrm{O}_{3}$ and $7 \%$ mol- $\%$ of $\mathrm{ZnO}$, before ( $a, b, c, d$ and e) and after be soaked by one day in SBF (f and g). (Results from ref. 24)

Because their composition and the excellent textural properties, it would be expected a good enough in vitro bioactive for these doped MBGs. Thus, Figures $3 \mathrm{f}$ and $3 \mathrm{~g}$ correspond to the $0.2 \% \mathrm{Ce}_{2} \mathrm{O}_{3} \mathrm{MBG}$ after being soaked by 1day in a Simulated Body Fluid (SBF) at $37^{\circ} \mathrm{C}$ proposed by Kokubo et al [26]. These Figures probes the quick in vitro bioactive response of these samples because even after only one day of treatment the surface of the glass particles appear coated by the cauliflower-type particles characteristic of an hydroxycarbonate apatite layer (HCA) which presence use to be indicative of the in vitro bioactive behavior of an investigated material [27]. The correspondent EDS spectrum indicates that the layer is mainly composed by calcium and phosphorous and the study by Fourier Transformed Infrared (FTIR) Spectroscopy not shown also allows detecting the presence of the characteristic bands of phosphate in a 
crystalline environment. This quick in vitro bioactive response, in terms of the formation of the HCA layer was exhibited by all the scaffolds containing $\mathrm{Ce}_{2} \mathrm{O}_{3}$ and $\mathrm{Ga}_{2} \mathrm{O}_{3}$. However in the case of the $\mathrm{ZnO}$-substituted MBGs the presence of $\mathrm{Zn}^{2+}$ ions modified the HCA formation process hindering the formation of the HCA layer.

In summary, at the levels of substitution with $\mathrm{Ce}^{3+}, \mathrm{Ga}^{3+}$ and $\mathrm{Zn}^{2+}$ ions investigated, the glass powders maintain mesoporosity and a quick in vitro bioactive response. However, some differences in the in vitro bioactivity kinetic were observed as a function of the composition. For these properties MBG including Cerium, Galium or Zinc are good candidates for bone TE applications. For this application the capacity of the scaffolds to load and release biomolecules in a controlled way was investigated. In our first attempt our group select Curcumin as a model drug [28]. The MBG powders showed capability to release the drug although a strong interaction between the drug and the added elements such as $\mathrm{Ga}^{3+}$ ions was observed. Evidently this ion was added to upgrade the MBGs but they interacted with Curcumin molecules increasing the load capacity but decreasing also the release process. In this way, for $3.5 \% \mathrm{Ga}_{2} \mathrm{O}_{3}$ the drug remained into the mesopores without being able to be released to the surrounding medium.

\section{Textural properties and bioactivity of substituted MBG scaffolds}

\section{$\mathrm{Ga}^{3+}, \mathrm{Ce}^{3+}$, and $\mathrm{Zn}^{2+}$ substituted MBG scaffolds}
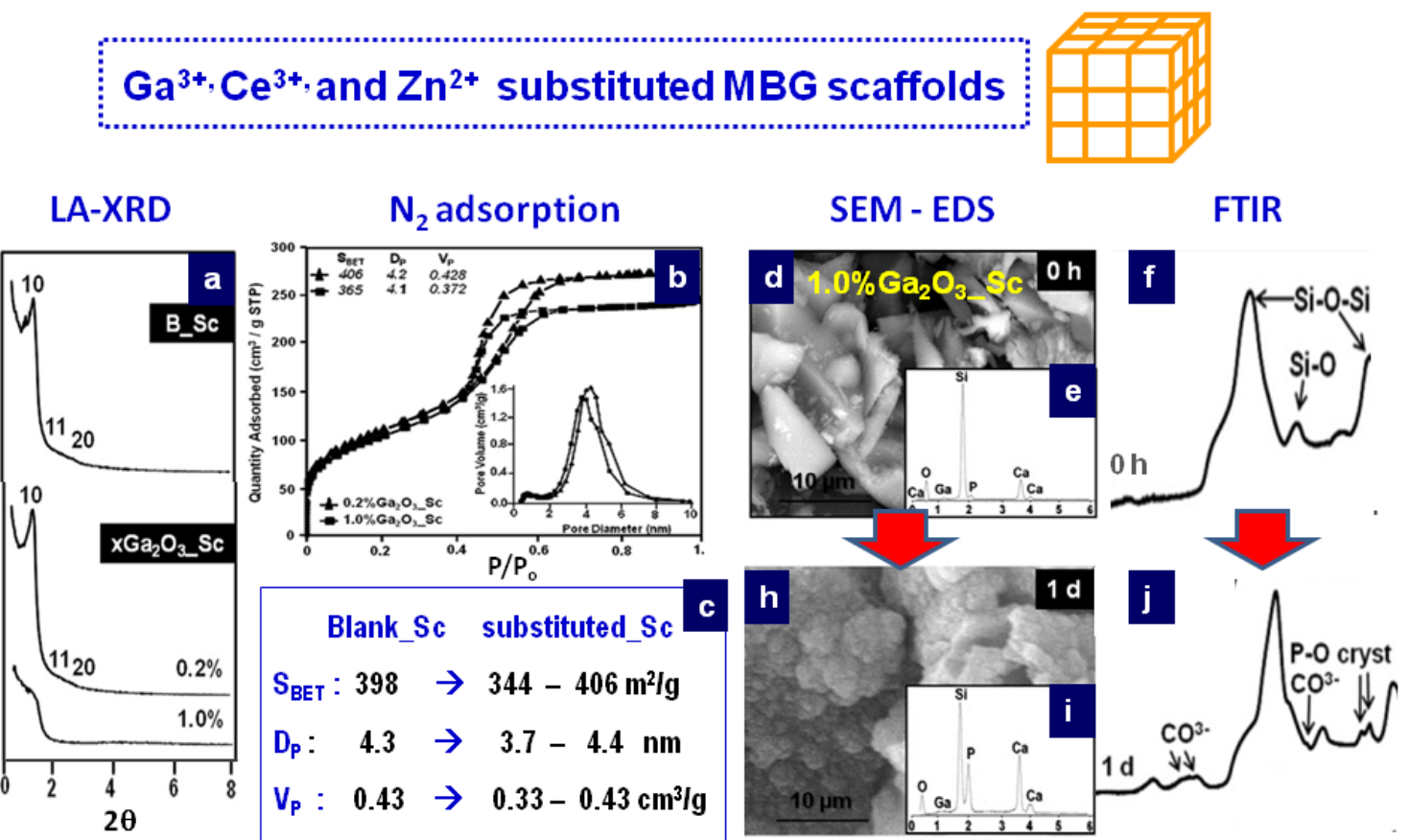

Figure 4. Physical-chemical characterization of $3 \mathrm{D}$ scaffolds based on the $15 \% \mathrm{CaO}-5 \% \mathrm{P}_{2} \mathrm{O}_{5}-80 \% \mathrm{SiO}_{2}$ MBG substituted by amounts below 1 mol- $\%$ of $\mathrm{Ce}_{2} \mathrm{O}_{3}$ or $\mathrm{Ga}_{2} \mathrm{O}_{3}$ and $2 \%$ mol- $\%$ of $\mathrm{ZnO}$, before (a, b, c, d, e and $\mathrm{f}$ ) and after be soaked 1 day in $\operatorname{SBF}(\mathrm{h}, \mathrm{i}$ and $\mathrm{j}$ ). (Results from ref. 28) 
Different conformation methods can be used to obtain MBG scaffolds (MBG_Sc) including porogens, electrospinning, supercritical processing or freeze-drying from suspensions using replicas of porous sponges. In our studies rapid prototyping (RP) 3D printing was used because it allows the processing of scaffolds with complex geometries and fine structures with a control of porosity [29]. MBG powders are milled and sieved to obtain grains below $32 \mu \mathrm{m}$ that are suspended in dichloromethane. This suspension is added to a solution of polycaprolactone in dichloromethane and the mixture allowed to evaporate until a paste with the appropriate consistency for injection is formed. The paste is introduced into a polyethylene injection cartridge of an EnvisionTEC GmbH 3-D Bioplotter ${ }^{\mathrm{TM}}$ printing device to obtain pieces that are dried at $70{ }^{\circ} \mathrm{C}$ and calcined at 500 ${ }^{\circ} \mathrm{C}$ to obtain the MBG_Scs.

The hierarchical porosity of the scaffolds implies certain sacrifice of their mechanical properties which limits the clinical uses of the constructs formed by a bioceramic scaffold decorated with signal molecules and cells. However several authors have added specific elements to the MBG_Sc to improve its mechanical properties. For instance, Zhang et al has recently reported the synthesis of Sr-containing scaffolds with uniform interconnected macropores and high porosity which exhibit a compressive strength around 170 times that of polyurethane foam template MBG scaffolds [30]. This can be a good strategy to increase the mechanical properties because other attempts of our group as the increase of the heating temperature slightly increased the mechanical properties but with a severe decrease of the in vitro bioactive response (unpublished results).

Figure 4 depicts some results of the physical chemical characterization of MBG scaffolds with compositions obtained by substituting the $15 \% \mathrm{CaO}-5 \% \mathrm{P}_{2} \mathrm{O}_{5}-80 \% \mathrm{SiO}_{2}$ (in mol-\%) glass with up to $1.0 \%$ of $\mathrm{Ce}_{2} \mathrm{O}_{3}$ or $\mathrm{Ga}_{2} \mathrm{O}_{3}$ or up to $2.0 \%$ of $\mathrm{ZnO}$. Figures $4 \mathrm{a}, \mathrm{b}, \mathrm{c}$, d, e, and f correspond to the untreated scaffolds, whereas Figs $4 \mathrm{~h}, \mathrm{i}$ and $\mathrm{j}$, corresponds to MBG_Sc after being soaked for 1 day in SBF, in order to evaluate their in vitro bioactive response.

LA-XRD patterns of Figure 4a show that the ordered mesoporous arrangement is well maintained in Blank scaffold and also in that doped with $0.2 \% \mathrm{Ga}_{2} \mathrm{O}_{3}$. However, in the $1 \% \mathrm{Ga}_{2} \mathrm{O}_{3}$ scaffold the manipulations necessary to obtain the scaffolds by rapid prototyping [28] i. e. grinding, obtaining a paste, 3D printing layer by layer and heating to eliminate the polymer; greatly deteriorate the mesoporous order, as it is indicated for the presence only of a shoulder in the LA-XRD pattern. As it was determinate by 
Transmission Electron Microscopy (TEM), results not shown, in these scaffolds a wormlike order of mesoporous was observed. However, for the scaffold with $2.0 \% \mathrm{ZnO}$, a clear maximum in the LA-XRD pattern in was present.

Fig. $4 \mathrm{~b}$ depicts $\mathrm{N}_{2}$ adsorption isotherms of two Gallium containing MBG_Sc. The characteristics of these curves are the same than those of the MBG powders already described in the previous section. In Figure 4c the most significant values of the textural properties are indicated. If we compare the $S_{\text {BET }}$ of Blank MBG powder, $515 \mathrm{~m}^{2} / \mathrm{g}$, with that of Blank MBG_Sc that is $398 \mathrm{~m}^{2} / \mathrm{g}$ and the lower of the doped MBG_Sc that is 344 $\mathrm{m}^{2} / \mathrm{g}$, we confirm that these looses are acceptable if compared with the biological benefits that suppose the obtaining of $3 \mathrm{D}$ scaffolds and the inclusion of therapeutic metallic elements. As it can be observed in Fig 4c, the pore volume and pore diameter also experience tolerable decreases.

Figures 4d, e and f, correspond to the $1.0 \%$ of $\mathrm{Ga}_{2} \mathrm{O}_{3} \mathrm{MBG}_{-} \mathrm{Sc}$ untreated and Figures $4 \mathrm{~h}, \mathrm{I}$ and $\mathrm{j}$ to the same scaffold after be treated by one day in SBF. As it can be observed, after this treatment there are clear evidences that the glass was coated by an HCA layer indicative of a very quick bioactive response.

Therefore the scaffolds obtained with the doped MBG exhibit attractive textural properties as well as a bioactive behavior. Thus, the additional features theoretically introduced by the therapeutical metallic elements were investigated. The possible antibacterial capability of scaffolds enriched with Gallium and Zinc is analyzed in the next section.

\section{Antibacterial properties of $\mathrm{ZnO}$ containing MBG scaffolds}

An important possible application of these MBG scaffolds is the bactericide effect of specific cations such as $\mathrm{Zn}^{2+}$ or $\mathrm{Ga}^{3+}$. The interest in this case would be to check if the scaffolds were able to exhibit a clear antibacterial capability against one of the bacteria present in the most part of the prosthesis infections after surgery. Simultaneously it would be needed that the ions released to the medium does not convert in non biocompatible to these scaffolds. 


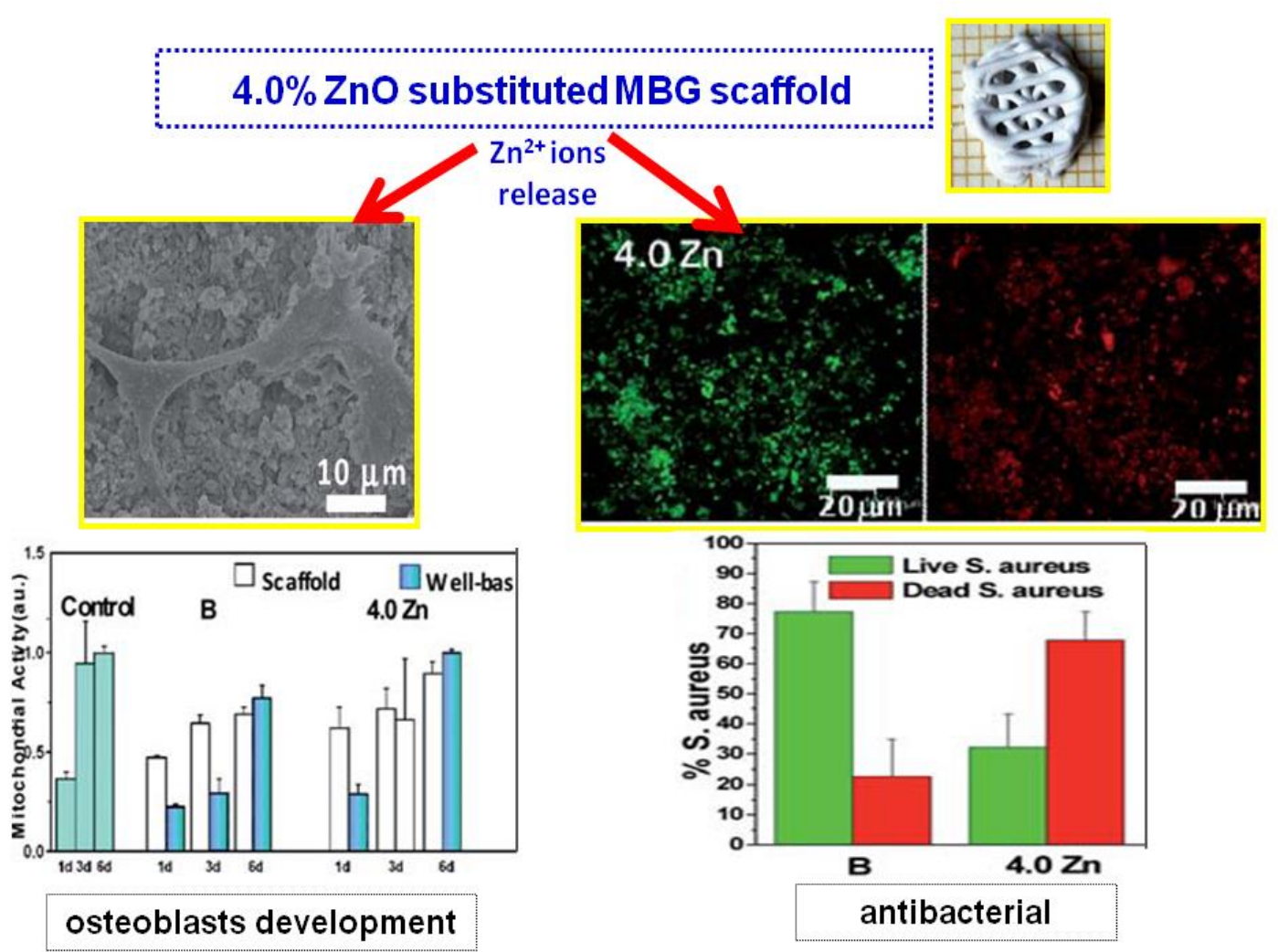

Figure 5. Left: in vitro biocompatibility study in osteoblastic-like cells and right: in vitro antibacterial capacity against $\mathrm{S}$. Aureus of $15 \% \mathrm{CaO}-5 \% \mathrm{P}_{2} \mathrm{O}_{5}-80 \% \mathrm{SiO}_{2} \mathrm{MBG}$ scaffolds containing $4 \%$ mol- $\%$ of $\mathrm{ZnO}$. (Results from ref. 31).

In Figure 5 is shown the more important results obtained after the study of biocompatibility and antibacterial capacity of some MBG_Sc based on the glass $15 \% \mathrm{CaO}-5 \% \mathrm{P}_{2} \mathrm{O}_{5}-80 \% \mathrm{SiO}_{2}$ doped with $4 \%$ of $\mathrm{ZnO}$ [31]. As it was indicated in the introduction, $\mathrm{ZnO}$ was included because it exhibits several positive biological effects including the antibacterial capability. Effectively the infection of prosthesis is one of the most important problems arising when a material is implanted into the body. This importance is going to increase in the future with the organization of the pathogens bacteria into biofilms resistant to many families of antibiotics. For this reason new imaginative approaches must be attempted and one of them can be the inclusion of elements with declared antibacterial capacity such as $\mathrm{Zn}^{2+}$ or $\mathrm{Ga}^{3+}$. It must be mentioned that the possible bactericide capacity of the inclusion of $\mathrm{Ga}_{2} \mathrm{O}_{3}$ was investigated but in this case the $\mathrm{Ga}^{3+}$ ions remains into the glass network without exhibit the sample antibacterial capability.

As it can be in the Figure, the unsubstituted MBG_Sc, i. e. Blank used as a control group exhibit certain antibacterial capability against $\mathrm{S}$. Aureus because the Silicon and Calcium ions. However, the inclusion of $4 \% \mathrm{ZnO}$ in the scaffolds drastically increased 
the amount of S. Aureus dead compared with the control group. Nevertheless it is important to cheek if materials releasing so high amounts of $\mathrm{Zn}^{2+}$ ions remain to be biocompatible. On the right part of the figure it can be observes the osteoblast development investigated in both the well-base and in extracts of culture medium after the soaking $\mathrm{f}$ the $\mathrm{Zn}$-loaded scaffolds for 1, 3 and 6 days. For substitutions as high as 7\% $\mathrm{ZnO}$ (results not shown) the obtained material was not biocompatible indicating that the concentration of the extra elements is a critical point that must be considered.

\section{Conclusions}

The inclusion of therapeutically active metallic ions in MBGs and their processing by rapid prototyping in 3D scaffolds slightly decreases the textural properties (surface area and porosity) and the in vitro bioactive response in fluids mimicking human plasma. However these values are so high in the ternary $\mathrm{CaO}-\mathrm{P}_{2} \mathrm{O}_{5}-\mathrm{SiO}_{2} \mathrm{MBG}$ s that they remain high enough to allow for the use of ion-substituted MBG scaffolds in bone TE applications. MBGs are excellent materials to employ as the base for the 3D scaffolds because of their inherent ordered mesoporosity which is not destroyed during the scaffolds processing nor during the inclusion of therapeutical elements. Thus, this material can be loaded with biomolecules that exert a synergic effect with the metallic ions.

\section{Future perspectives}

3D scaffold based on $\mathrm{CaO}-\mathrm{P}_{2} \mathrm{O}_{5}-\mathrm{SiO}_{2}$ MBGs enriched with metallic oxides of elements with biological significance is a promising subject for bone TE. The resultant materials exhibit more than acceptable textural properties and vitro bioactivity. This plus the added value of substituent ions make them excellent candidates as scaffolds in bone TE.

Results obtained show that much more work must be performed in this field because unexpected results are sometimes obtained. For instance, some ions such as $\mathrm{Ga}^{3+}$ actuate as intermediate ions between network formers and network modifiers. Furthermore, the acid of Lewis character of this cation also pushes it into the glass surface instead of being homogeneously distributed over the entire glass network. In this position there is a strong interaction with the basic Lewis centers of some of the possible substances to be adsorbed and released into the glasses mesopores. In fact, a higher interaction with the matrix will produce higher taxes of adsorption of the drug, but this 
high interaction hinders the release of the adsorbed biomolecules making the use of this specific ion not useful at least at certain specific concentration levels.

At the present $\mathrm{Ga}^{3+}$ ions are involved in new and very promising strategies to fight against infections that will not develop bacterial resistances as antibiotics or antimicrobial peptides do [32]. $\mathrm{Ga}^{3+}$ ions compete with $\mathrm{Fe}^{3+}$ ions uptake by the siderophores necessary for the bacteria biofilms survival [33].

Other factors that must be taken into account are due to the high bioactivity of these materials. The quick formation of an HCA layer can hinder or slow down the liberation of the specific biomolecules included in the mesopores or even the release of the ions included with antibacterial or other purposes.

On the other hand, it was recently reported the ability of $\mathrm{Ce}^{3+} / \mathrm{Ce}^{4+}$ containing bioactive glasses to inhibit oxidative stress by mimicking the catalase enzyme activity [34].

Consequently the inclusion of every specific inorganic ion in the MBG scaffolds, and even the specific concentration of the cation need to be deeply investigated before translated into clinical applications.

\section{Acknowledgements}

Financial support of Ministerio de Ciencia e Innovacion (MICINN) through the project MAT2012-35556 and Ministerio de Economía y Competitividad through the Spanish and European Network of Excellence CSO2010-11384-E is acknowledged. The authors wish to thank also to the staff of the ICTS Centro Nacional de Microscopia Electrónica and Centro de Diffraction de Rayos X of Universidad Complutense de Madrid (Spain).

\section{References}

1. L. L. Hench, R. J. Splinter, W. C. Allen, T. K Greenlee, J. Biomed. Mater. Res., 1971, $2,117-41$.

2. L. L. Hench, J. Am. Ceram. Soc. 1991, 74, 1487-510.

3. X. Yan, C. Yu, X. Zhou, J. Tang, D. Zhao. Angew. Chem. Int. Ed. 2004, 43, 5980-4.

4. A. López-Noriega, D. Arcos, I. Izquierdo-Barba, Y. Sakamoto, O. Terasaki, M. ValletRegí, Chem. Mater. 2006, 18, 3137-44.

5. L. L, Hench, J. M. Polak. Science 2002; 295:1014-7.

6. A. J. Salinas, M. Vallet Regi, RSC Advances, 2013, 3, 11116-31

7. A. J. Salinas, P. Esbrit, M. Vallet Regi, Biomater. Sci., 2013, 1, 40-51.

8. J. R. Jones, Acta Biomater. 2013, 9, 4457-86.

9. M. Vallet-Regi, C. V. Ragel, A. J. Salinas. Eur. J. Inorg. Chem. 2003:1029-42.

10. A. J. Salgado, O. P. Coutinho, R. L. Reis, Macromol. Biosci., 2004, 4, 743-65. 
11. C. Wu, J. Chang, J. Control. Release, 2014, 193, 282-95.

12. C. Wu, J. Chang, Interface Focus, 2012, 2, 292-306.

13. C. Wu, Y. Luo, G. Cuniberti, Y. Xiao, M. Gelinsky. Acta Biomater. 2011, 7, 2644 50.

14. A. Hoppe, N. S. Gueldal, A. R. Boccaccini, Biomaterials 2011, 32, 2757-2774

15. A. Hoppe, V. Mouriño, A.R. Boccaccini. Biomater. Sci., 2013, 1, 254-6.

16. V. Mourino, J. P. Cattalini, A. R. Boccaccini, J. R. Soc. Interface, 2012, 9, 401-419

17. M. Vallet-Regi, A. J. Salinas, J. Ramirez-Castellanos, J. M. Gonzalez-Calbet, Chem. Mater. 2005, 17, 1874-79.

18. I. Izquierdo-Barba, A. J. Salinas, M. Vallet-Regi, Int. J. Appl. Glass Sci., 2013, 4, $149-61$

19. C. Leonelli, G. Lusvardi, G. Malavasi, L. Menabue, M. Tonelli. J. Non-Cryst. Solids 2003, 316, 198-216.

20. S. P. Valappil, D. Ready, E. A. Abou Neel, D. M. Pickup, W. Chrzanoweki, L. A. Ó Dell, R. J. Newport, M. E. Smith, M. Wilson, J. C. Knowles. Adv. Funct. Mater. 2008, $18,732-42$.

21. A. Grandjean-Laquerriere, P. Laquerriere, E. Jallot, J. M. Nedelec, M. Guenounou,

D. Laurent-Maquin, T. M. Phillips, Biomaterials, 2006, 27, 3195-200

22. X. Wang, X. Li, A. Ito, Y. Sogo, Acta Biomater. 2013, 7, 3638-3644.

23. C. J. Brinker, Y. Lu, A. Sellinger, H. Fan. Adv Mater, 1999, 11, 579-85.

24. A. J. Salinas, S. Shruti, G. Malavasi, L. Menabue, M. Vallet-Regi. Acta Biomater. 2011, 7, 3452-8.

25. L. J Ji, Y. F. Si, H. F. Liu, X. L. Song, W. Zhu, A. P. Zhu, Micropor. Mesopor. Mater. 2014, 184, 122-126.

26. T. Kokubo, H. Takadama. Biomaterials. 2006, 27, 2907-15.

27. S. Shruti, A. J. Salinas, E. Ferrari, G. Malavasi, G. Lusvardi, A. L. Doadrio, L. Menabue, M. Vallet-Regi, Micropor. Mesopor. Mater, 2013, 180, 92-101.

28. S. Shruti, A. J. Salinas, G. Lusvardi, G. Malavasi, L. Menabue, M. Vallet-Regi, Acta Biomater., 2013, 9, 4836-44.

29. S. F. Yang, K. F. Leong, Z. H. Du, C. K. Chua. Tissue. Eng, 2002, 8, 1-11.

30. J. Zhang, S. Zhao, Y. Zhu, Y. Huang, M. Zhu, C. L. Tao, C. Q. Zhang. Acta Biomater. 2014, 10, 2269-81.

31. S. Sanchez-Salcedo, S. Shruti, A. J. Salinas, G. Malavasi, L. Menabue, M. ValletRegi, J. Mater. Chem. B, 2014, 2, 4836.

32. C. Bordi, S. de Bentzmann. Annals of Intensive Care 2011 1:19.

33. A. Ross-Gillespie, M. Weigert, S. P. Brown, R. Kummerli, Evolution, Medicine, and Public Health 2014, 18-29.

34. V. Nicolini, E. Gambuzzi, G. Malavasi, L. Menabue, M. C. Menziani, G. Lusvardi, A. Pedone, F. Benedetti, P. Luches, S. D’Addato, S. Valeri. J. Phys. Chem. B, 2015 DOI: $10.1021 / \mathrm{jp} 511737 \mathrm{~b}$ 